Review Article

\title{
A Review of Asphaltic Crack Healing Approaches and Its Mechanism
}

\section{Mohd Fahmi Haikal Mohd Ghazali, ${ }^{1}$ Mohd Rosli Mohd Hasan (D, ${ }^{1}$ Anasyida Abu Seman (D), Dillon Dipagk Dorett, ${ }^{1}$ Najib Mukhtar, ${ }^{1,3}$ and Ramadhansyah Putra Jaya $\mathbb{D}^{4}$}

\author{
${ }^{1}$ School of Civil Engineering, Universiti Sains Malaysia, Pulau Pinang 14300, Malaysia \\ ${ }^{2}$ School of Materials and Mineral Resources Engineering, Universiti Sains Malaysia, Pulau Pinang 14300, Malaysia \\ ${ }^{3}$ Department of Civil Engineering, Bayero University Kano, Kano 700241, Nigeria \\ ${ }^{4}$ Department of Civil Engineering, College of Engineering, Universiti Malaysia Pahang, Gambang, Kuantan 26300, \\ Pahang, Malaysia \\ Correspondence should be addressed to Mohd Rosli Mohd Hasan; cerosli@usm.my
}

Received 22 July 2021; Accepted 21 November 2021; Published 7 December 2021

Academic Editor: Akbar Heidarzadeh

Copyright (C) 2021 Mohd Fahmi Haikal Mohd Ghazali et al. This is an open access article distributed under the Creative Commons Attribution License, which permits unrestricted use, distribution, and reproduction in any medium, provided the original work is properly cited.

\begin{abstract}
The concept of self-healing has an excellent potential to extend the life of asphalt pavement. This technology can be considered a sustainable technology due to its ability to reduce the utilization of asphalt mixture production materials used for road maintenance, polluting the environment. It is a complex physicochemical process wherein the molecular diffusion healing mechanisms in asphalt materials are inspired by self-healing polymeric systems, which describe the self-recovery behaviors based on polymer chain dynamics. Several methods have been adopted to improve the self-healing of asphalt, one of which is induction healing. It is the process of heating the asphalt pavement incorporated with an electrically conductive material such as steel fibers, wherein asphalt healing is undertaken via electric field induction. Induction healing via induction heating occurs with eddy current where the electric current flows within the conductive fibers when magnetically susceptible under the magnetic field. Microwave heating is another self-healing method similar to induction in which magnetic radiation is employed to treat asphalt mixtures instead of the electric field-induced induction healing processes. The conductive fibers can absorb the electromagnetic (EM) waves to convert them into heat energy through doublet polarization, interface polarization, and electrical conduction dissipation when placed in the microwave field. These two types of heating systems, which are induction heating and microwave heating, are compared and discussed thoroughly in this study. Finally, some recommendations for the future development of selfhealing asphalt are proposed.
\end{abstract}

\section{Introduction}

1.1. Asphalt Concrete in Civil Engineering. Asphalt concrete (AC) consists of a mixture of bitumen and aggregate produced as a composite of viscoelastic and nonviscoelastic materials used primarily on civil engineering structures such as airports and highways $[1,2]$. It is a material that deforms at high temperatures and can become brittle at low temperatures [3]. Asphalt concrete is utilized to build flexible pavements and road networks that connect one city to another. According to the Asia Trade Hub website,
Malaysia's road network covers 144,403 kilometers, where 116,169 kilometers are paved and 1,821 kilometers are expressways [4]. However, after several years in service, the flexibility and relaxation capacity of these asphalt concrete roads gradually decrease due to the repeated daily traffic loads and environment interchange (mainly temperature and moisture) [5]. The asphalt binder becomes brittle, lowering its adhesion capabilities, thereby causing the separation of aggregates and the binder [2]. Therefore, from time to time, such paved asphalt concrete needs to be maintained to ensure the estimated lifespan of the road is 
achieved while preventing traffic accidents from occurring due to the asphalt pavement distress [6]. One of the primary indications of asphalt pavement distress is cracks. The cracking mechanism related to bituminous materials is complicated and depends on traffic loading conditions and atmospheric temperatures. Atmospheric conditions that can cause oxidation are one of the main reasons for the degradation of asphalt mixtures. This event is also known as aging, where the asphalt binders and their viscoelastic properties become stiffer compared to their original states. As time goes by, the materials will reach a certain level of stiffness that causes them to become brittle, hence unable to resist and recover during loading/unloading conditions, which eventually leads to cracking at microscopic and macroscopic levels. Many researchers have conducted studies to solve the damage caused by cracking failure via promoting crack closure at an early stage. Although the capability of asphalt as a self-healing material has been proven, its ability to heal is obviously limited due to nonstop traffic loading and is not enough to accommodate the asphalt degradation that keeps happening due to atmospheric conditions. Therefore, the induction of self-healing technology into asphalt mixtures was investigated and introduced to overcome these problems [7].

1.2. Asphalt as Self-Healing Materials. Asphalt concrete is a self-healing material that has the capability of restoring some of its functionality. This usually occurs due to the potential of bitumen to behave like a Newtonian fluid at temperatures ranging from 30 to $70^{\circ} \mathrm{C}$, depending on the type of bitumen [8]. Dai et al. [3] reported the healing behavior of asphalt as the self-recovery capability of asphalt materials under specific loading and/or environmental conditions, especially during rest time. $\mathrm{Xu}$ et al. [9] also mentioned that the fundamental of self-healing in asphalt pavement depends on the initiation of a "mobile phase" during the rest period that gradually results in crack closure. The self-healing material will regain a certain rate of its functionality where the bitumen can flow and diffuse to close its microcracks when it is not exposed to loads $[10,11]$. This process mainly occurs due to the viscosity and gravitational force acting on the bitumen [12]. However, it would not be possible to halt traffic on the roads and allow enough self-healing and recovery at ambient temperatures [13]. Hence, the healing of asphalt mixtures becomes somewhat influenced by external conditions, wherein further propagation of micro-to macrocracks results from consistent loading, loading level, number of load repetitions, aging, and moisture conditions [14].

The primary goal of self-healing technology is to ensure that the material heals after being subjected to fatigue damage. It is a technology that plays a role mainly during maintenance in areas where pavement distresses occur. Even without a self-healing technology, a fatigued pavement can be restored but it will consume a lot of time and energy to recover its initial performance. Thus, this technology aims to overcome the local or global level of damage, extend, and renew the damaged part, system, or component [15]. Fatigue damage occurs when shear forces are exerted on the stones within the road surface. This causes strain within the adhesive bridges between the stones. With recurring forces (repeated traffic load), "fatigue taxation" will occur. Fatigue in these adhesive bridges leads to the first stage of the three-stage damage mechanism: crack initiation. The second stage is crack growth, which is followed by the third stage: a complete breakage of a singular adhesive bridge [16].

According to Tabaković and Schlangen [17], the selfhealing or self-repairing property of a material is referred to as "its ability to substantially return to an original, proper operating state or condition before exposure to a dynamic and susceptible environment by making the necessary adjustments to restore to normality and/or its ability to resist the formation of irregularities and/or defects." The repair is, in principle, an automatic initiated response to damage or failure. In order to repair the damage, the self-healing system must be able to identify and perform the restoration mechanism. Fischer [15] states that repair is classified into two categories:

(1) Attributive repair: Attempting to restore the attributes of the system to their initial state.

(2) Functional repair: To restore the functionality of the system. If the functionality cannot be fully reinstated, the residual resources are utilized to supplement the existing functionality.

Moreover, self-healing is also known as a very complex physicochemical process. The molecular diffusion healing mechanisms in asphalt materials are derived based on selfhealing polymeric systems, which describe its self-recovery behavior based on polymer chain dynamics [18]. Wool and O'Connor [19] divided the theory of crack healing into five stages based on molecular interdiffusion. These five stages are as follows:

(1) The surface rearrangement stage that affects the diffusion initiation function and topological features of the interface

(2) Approach stage that affects the healing mode

(3) The wetting stage that controls the wetting distribution of the two faces of microcrack

(4) Diffusion stage that develops the mechanical properties during healing

(5) Randomization stage that involves complete loss of memory of the crack interface

According to Tabaković and Schlangen [17], wetting, diffusion, and randomization are the only primary stages in an autonomous asphalt self-healing process. Meanwhile, Qiu et al. [14] mentioned that self-healing is influenced by the hydrogen bond and van Waals forces between molecules.

Moreover, Sun et al. [2] observed an ongoing event between healing and fatigue in pavement during its service life. This process was noticed to be dependent upon variations in the pavement temperature. Figure 1 shows the schematic diagram of its mechanism. Moreover, asphalt type and properties also influence the wetting capacity of 


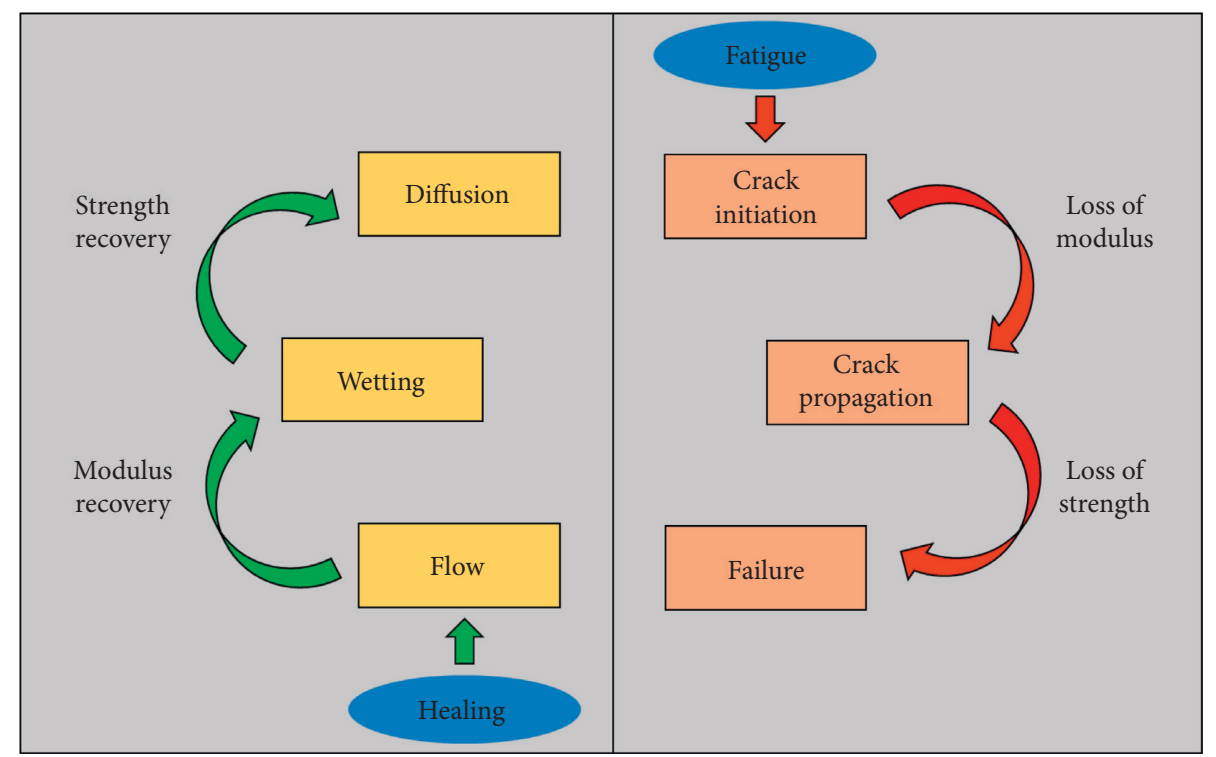

FIgURE 1: Three-step healing mechanism in asphalt [2].

aggregate phases during healing. The wetting rate is directly proportional to the asphalt surface energy. Hence, the diffusion ability can be said to correspond to the portability of the asphalt molecules. Nonetheless, some researchers have discovered that the asphalt consisting of more molecules with fewer and longer branched chains has higher molecule mobility than smaller chains and larger branches [2].

Several methods of inducing self-healing in asphalt pavement design have been presented and critically analyzed concerning their functionality, design, and performance to prolong its service life [20]. Some of the methods of selfhealing, as proposed by Tabaković and Schlangen [17], are as follows:

(1) Incorporation of nanoparticles

(2) Induction healing

(3) Rejuvenation

This paper will focus on the mechanisms of induction healing using different approaches based on different studies reported in the literature.

\section{Induction Healing Technology}

The practice of heating asphalt surface layer "in situ" has been in use for a long time. Despite the poor heat conductivity of asphalt due to mineral aggregates, the road surfaces were heated up using infrared heaters. The desired level of heating to the asphalt layers especially at its lowest layer was obtained by overheating the asphalt for a long period of time by using "additive heat radiation." One of the disadvantages of this method was accompanied by great waste of energy and constant burning of the bitumen in the asphalt surface layer [16]. The poor heat conductivity of the mineral aggregates in the asphalt mixture and too much loss in heat energy were addressed by using electrically conductive asphalt.
The first induction heating technology was invented by Minsk [21]. His invention was based on preventing ice and snow accumulation on flexible pavements by adding graphite particles in an asphaltic concrete to make it electrically conductive. García et al. [22] and Liu et al. [13] defined a conductive asphalt concrete as the portion of asphaltic concrete that contains the bitumen, aggregates, and conductive particles such as carbon fibers. Hence, an induction heating device can effectively achieve localized heating of the particles through heat diffusion, thereby heating the binder and healing the cracks [23]. Asphaltcontaining conductive particles are exposed to a high frequency alternating electromagnetic field during induction heating by inducing eddy currents in electrically and magnetically susceptible materials. The induced eddy currents heat the metallic fibers while the heat energy diffuses into the bitumen to increase its temperature. Such induction mechanism is conducive in aiding asphalt mixtures heal quickly because bitumen mostly behaves as a Newtonian fluid when its temperature is above its softening point [24]. Hassan et al. [55] observed that a very small volume of fibers of more than $0 \%$ served to increase binder temperatures via induction heating. Meanwhile, García et al. [22] found that there is an optimum volume of fibers for each mixture below which the conductivity of the material suddenly drops to that of a nonconductive material. However, above such volume of fiber, they experienced difficulties in mixing while the increase in the conductivity was also very low [22]. Furthermore, García et al. [25] reported that the resistivity of the mastic sample would keep reducing with the volume of conductive additive. Until a certain level of conductive volume content, the increasing of conductive volume will not reduce the resistivity of the mastic sample any further. This can be seen in Table 1 based on a study by García et al. [25] where the conductive additive reaches its peak for steel wool, with a $5.83 \%$ steel wool + graphite and $6.54 \%$ steel wool+graphite at approximately 2,1 , and $1 \Omega \mathrm{m}$, 
TABLE 1: Conductive particles-bitumen ratio for asphalt mortar systems at different conductive additive content [25].

\begin{tabular}{lcccc}
\hline Conductive additives content (vol \%) & Graphite & Steel wool & $\begin{array}{c}\text { Log resistivity }(\Omega \mathrm{m}) \\
\text { 5.83\% steel wool + graphite }\end{array}$ & 6.54\% steel wool + graphite \\
\hline 5.5 & 11 & 9.5 & 9 & N/A \\
7 & 10.5 & 2 & 8.5 & 1 \\
10.5 & 9.8 & N/A & 8.3 & 1 \\
13 & 9.5 & N/A & 3 & 1 \\
15.5 & 8.8 & N/A & 1.5 & 1 \\
17 & 8.5 & N/A & 1 & 1 \\
20.5 & 8 & N/A & 1 & 1 \\
\hline
\end{tabular}

respectively. Further increment of steel wool content can cause the mixing to become harder and form a cluster ball. Thus, it is limited to approximately $6 \%$ steel wool content in his study. Next, the test was conducted on the asphalt mastic sample prepared with graphite (without steel wool), the resistivity keeps reducing due to the filler particle size of graphite where the connection between one particle and another particle to induce current are weaker compared to steel wool. This condition can be illustrated as in Figure 2 where the steel wool fibers form a connection between one and another to form a conductive asphalt mastic.

Furthermore, García et al. [22] and Dai et al. [3] utilized the gel permeation chromatography technique to test inducted healed specimens and noninducted specimens, which demonstrated the chemical properties of the asphalt, such as its averaged molecular weight not to be influenced by induction healing. Similarly, the effect of chemical composition was also observed to exhibit a strong influence on the induction healing properties of asphalt by which asphalt with higher small molecule content/large molecular content ratio combined with higher aromatics content had greater self-healing abilities than those with smaller molecular and lower aromatic contents [26].

2.1. Induced Healing via Induction Heating. Asphalt concrete mixtures are generally added with conductive fibers in order to improve their electrical conductivity so as to facilitate effective induction heating. The process of adding the steel fibers to the mixture is direct during mixing, without affecting the gradation of the mixture. Liu et al. [13] reported that the addition of long steel wool was more effective in making asphalt concrete electrically conductive for $9.5 \mathrm{~mm}$ steels long enough to conduct electric currents. Moreover, the performance of long fibers with small diameters was found by Sun et al. [27] to be better than short fibers with bigger diameters. This finding was also supported by Gao et al. [28] due to several benefits such as improving the flexural strength and particle loss resistance of the asphaltic concrete. However, asphalt mixtures with long fibers tended to form cluster balls and increase the air void content of the mixtures, which was associated with a reduction in the mechanical properties of the mixtures as reported by Norambuena et al. [29] and González et al. [30].

Based on such observations, Xu et al. [24] recommended the use of short and thick steel wool fibers with a diameter of $70-130 \mu \mathrm{m}$ and length $4.2 \mathrm{~mm}$ because it is quite easier to
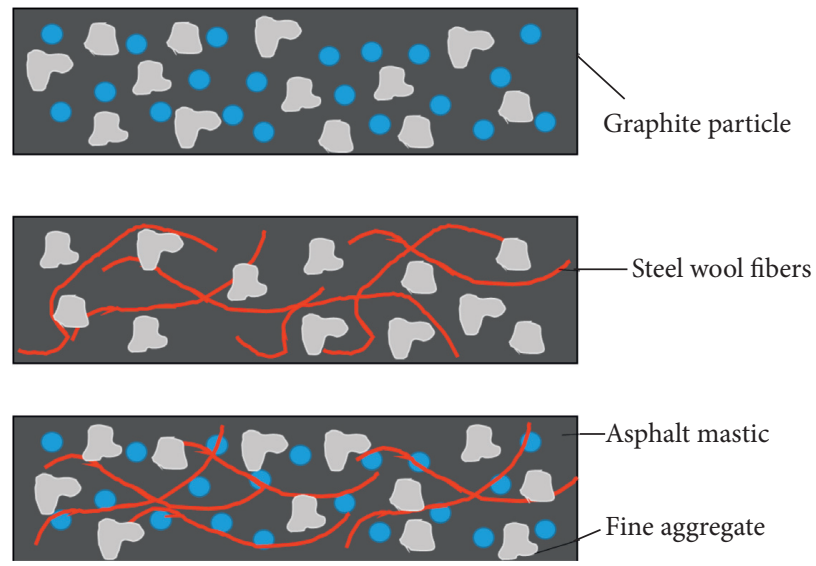

FIGURE 2: Illustration of asphalt mastic composition with and without steel wool and graphite.

mix using the standard mixing procedure at an optimal steel wool content of $6 \%$ by the volume of bitumen. Nonetheless, some studies such as those conducted by Ameri et al. [31] and Sun et al. [18] replaced a portion of the aggregate from the asphalt mixture with steel slags as conductive materials by which they attested to the fact that the steel slag-asphalt mixture showed a better performance in healing when the temperature distribution was more uniform. Furthermore, laboratory test results also evidently indicated the use of coarse steel slag aggregates in warm mix asphalt (WMA) mixture in the enhancement of the tensile strength, resilient modulus, Marshall stability, resistance to moisture damage, and resistance to permanent deformation of the mixture [31]. Similar reports on the mechanical performance of asphalt mixture were mentioned by Dai et al. [3] while investigating the induction healing effects of electrically conductive asphalt mastic and asphalt concrete beams through fracture-healing tests as asphalt mixture samples were observed to still maintain at least half of their original fracture strengths, after six fracture-healing cycles [32].

2.2. Induced Healing via Microwave Heating. The second technique used to increase the temperature of asphalt mixtures for the improvement of asphalt road maintenance was microwave radiation heating [33-35]. The preliminary analysis for production and cost was conducted by Bevacqua et al. [36]. The results show that the performance of microwave healing in terms of cost-saving for a lifespan of 100 years is improved compared to a traditional method, such as 
reconstructing the asphaltic layer that requires transportation and additional resource [37]. Microwave heating is usually considered a potential technique for stimulating the self-healing of composite materials, very much similar to induction heating. Asphalt mixtures here are mostly exposed to alternating electromagnetic fields under high frequencies (in the order of megahertz) by using an electromagnetic radiation device like a microwave, which is environmentally friendly due to the reduction of carbon dioxide emission $[37,38]$. This heating effect has been established to affect the properties of both water and bitumen in asphalt mixtures [35], wherein it induced a change in the orientation of their polar molecules as a result of alternating magnetic fields. As a result, the molecule's mobility becomes disrupted and impeded while their temperature increases. Generally, asphalt mixtures are not susceptible to heating with induction heating energy; however, the incorporation of metallic particles known as microwave absorbers in asphalt mixtures may help reflect the microwave radiation, thereby boosting its temperature susceptibility [39]. Hence, the incorporation of metallic and ferrous particles susceptible to electromagnetic radiation such as steel slag can help increase the heating rates of asphalt mixtures by absorbing and conducting more thermal energy to other components of the mixtures, that is, aggregates and bitumen [40]. The recommended sizes for the metallic particles of steel fiber as a microwave reflecting admixture by Deng et al. [41] are $0.4-0.8 \mathrm{~mm}$ and $0.5 \mathrm{~mm}$ length to width, respectively. Recent findings have established microwave heating to be more advantageous than induction heating in terms of its high heating efficiency (rapid heating), no direct contact with liquids, no air emissions, fast thermal response, precise temperature control, and selective energy absorption $[18,42,43]$. The rapid increase of total energy means that the sample can absorb more energy to increase the temperature [44]. Microwave heating proved to be more economical and effective than electromagnetic induction in promoting self-healing of asphalt mixture with steel wool and graphite [45]. A study by $\mathrm{Xu}$ et al. [46] also shows that microwave heating can alter the structure of air voids compared to induction heating. Lastly, the amount of power consumption and the optimal steel wool dosages on employing microwave heating have also been 10 times lower than required for electromagnetic induction heating $[47,48]$.

\section{Conductive Particles Used for Induction Healing}

The induction healing technology has ventured into the field of materials engineering in the last few years. The utilization of this technology has resulted in a revolution in the field of material sciences and engineering. Some of the applications of induction healing technology in engineering materials and its recovery performance are presented in Tables 2 and 3 , respectively.

Mostly steel fibers and steel wools are the prevalent materials utilized for both electromagnetic heating and induction heating of asphalt mixtures. As shown in Table 2, Liu et al. [11, 13, 50, 51] and Garcia et al. [23, 52] utilized steel fiber and steel wool for asphalt mixture induction and microwave radiation heating processes, while steel shavings, carbon fibers, and utensil steel wool have also been employed for crack healing procedures via both induction and microwave radiation heating mechanism [53-56]. Similarly, steel by-products such as slags, wools, and fibers have also been widely used in road pavements, due to their excellent mechanical properties, in terms of roughness, shape, angularity, hardness, polishing, and wear resistance $[56,57]$. Table 3 also proved that the healing performance of asphalt mixtures by several researchers was able to improve the healing by $50-100 \%$ depending on the type of conductive material used. Therefore, both induction and microwave heating systems are successful innovations that are able to increase the lifespan of the asphalt pavement and lower the maintenance cost.

$\mathrm{Wu}$ et al. [58] reported that the mechanical characteristics of carbon fiber-reinforced asphalt matrix had improved due to the nature of the insulating conductive polymer composites. The incorporated high-aspect-ratio carbon fibers were helpful to improve the conductivity of the insulating polymer matrix even at relatively low concentrations. Therefore, the utilization of steel in the pavement can be inferred to be quite suitable for both mechanical and healing performances $[59,60]$.

\section{Mechanism of Induction Heating}

The induction heating system comprises alternating power generators, induction coils, and electrically conductive steel fibers incorporated and dispersed between the mixture's interstices, as shown in Figure 3. The coil normally produces the magnetic field for a uniform amount of frequency under an alternating electric power supply. As shown in Figure 3, each conductive steel fibers within asphalt mixtures were induced. Based on Faraday's law, the presence of a magnetically susceptible and electrical material within a magnetic field leads to an electric current (eddy current) being induced upon it at the same frequency as the magnetic field. At the same time, the intensity of the current is proportional to the intensity of each coil circulation [61]. Induction heating in asphalt mixtures is usually generated through the dominant joule effect, dielectric hysteresis, and contact resistance between heated fibers. Joule heating (also known as resistive or ohmic heating) generates heat from electric energy due to the resistance imposed to current flow. In a solid or liquid with finite conductivity, electric energy is converted to heat through resistive losses in the material. This causes heat to be generated by the conductor via electron energy transfer to its atoms through electronelectron collisions, which spreads across all its atoms. The phenomena observed in the binder-conductor interfaces result in heat transfer between conductor and asphalt binder atoms; hence, uniform heating between both interfaces is achieved. The transfer of energy from the applied electric field results in unrecoverable heat loss between both atomic interfaces refers to its dielectric loss, hysteresis, or dissipation. The amount of energy transfer is also mainly dependent on the properties of both the conductor and binder used, 
TABLE 2: List of research studies on the different types of material used for induction healing.

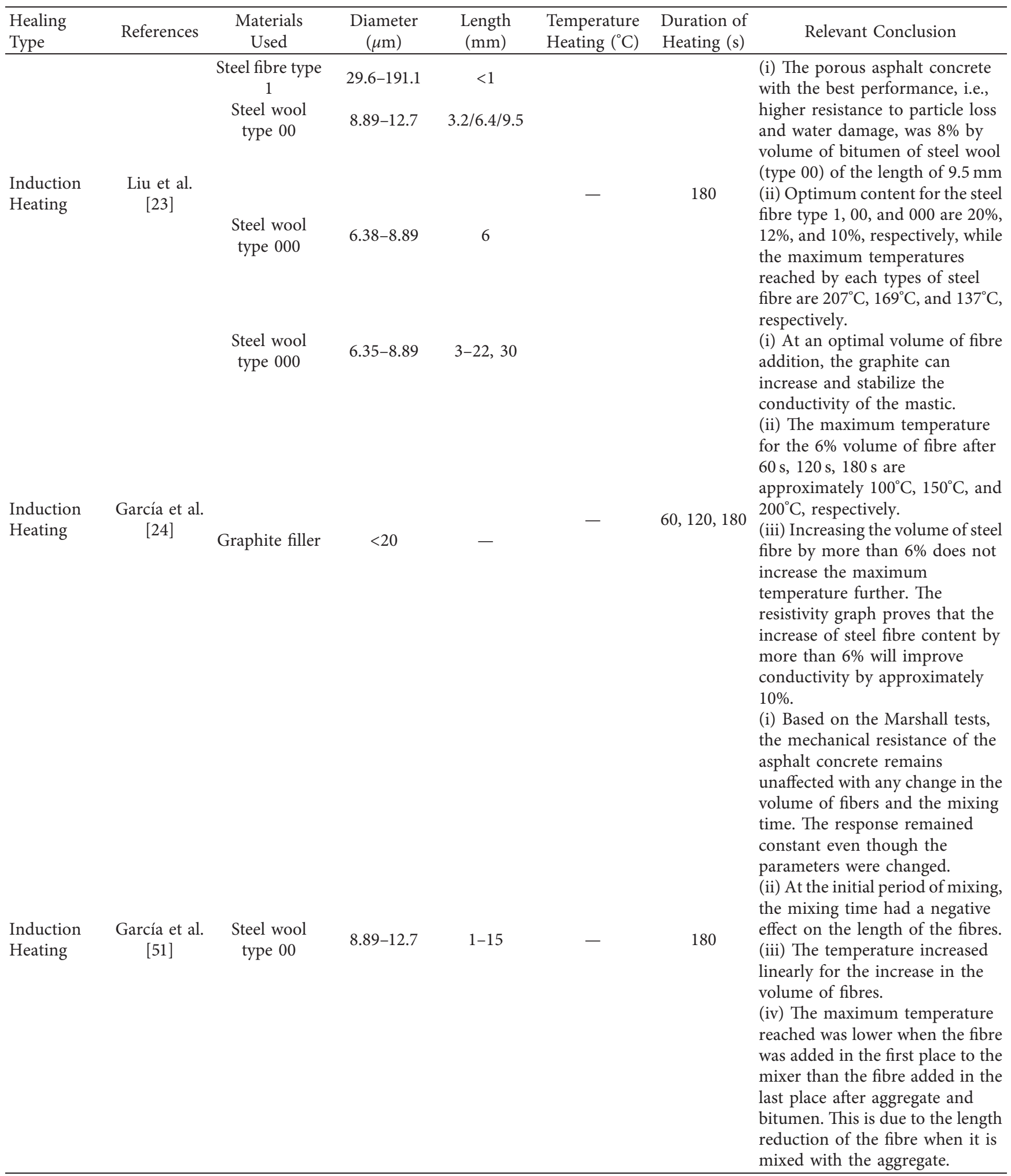


TABle 2: Continued.

\begin{tabular}{|c|c|c|c|c|c|c|c|}
\hline $\begin{array}{l}\text { Healing } \\
\text { Type }\end{array}$ & References & $\begin{array}{c}\text { Materials } \\
\text { Used }\end{array}$ & $\begin{array}{l}\text { Diameter } \\
(\mu \mathrm{m})\end{array}$ & $\begin{array}{l}\text { Length } \\
(\mathrm{mm})\end{array}$ & $\begin{array}{l}\text { Temperature } \\
\text { Heating }\left({ }^{\circ} \mathrm{C}\right)\end{array}$ & $\begin{array}{l}\text { Duration of } \\
\text { Heating (s) }\end{array}$ & Relevant Conclusion \\
\hline
\end{tabular}

(i) The mortar of porous asphalt concrete exhibits a higher nanoindentation modulus when strengthened with steel wool.

$\begin{array}{lccccc}\text { Induction } & \text { Liu et al. } & \text { Steel wool } & \text { 8.89-12.7 } & 10 & 30,50,70,85, \\ \text { Heating } & {[52]} & \text { type } 00 & & & 100\end{array}$

(ii) Heating of the beam fracture at $20^{\circ} \mathrm{C}$ does not result in any healing. The fracture recovery increased from 14.9 to $78.8 \%$ when the heating time is from 30 to $85^{\circ} \mathrm{C}$.

(i) The best outcome of healing effects is obtained for an optimal heating temperature of $85^{\circ} \mathrm{C}$.

Overheating may result in problems like swelling and binder drainage, inhibiting healing.

(ii) Performing induction heating multiple times can extend the $\begin{array}{lccccccc}\text { Induction } & \text { Liu et al. } & \begin{array}{c}\text { Steel wool } \\ \text { type } 00\end{array} & 8.89-12.7 & 10 & 70,85,100 & 180 & \begin{array}{c}\text { multiple time of porous asphalt } \\ \text { feating }\end{array} \\ \text { [53] } & \text { life }\end{array}$

Steel wool type 3

Steel wool type 1

Steel wool

Induction

Heating

García et al.

type 00

[54]

Steel wool type 0000

Steel fibres

Induction

Liu et al.

[11]

Steel slag
28.55

$70-130$

4.2

Replace

154.98

83.89

36.42

Short

fibres: 2.5 ,

Long

fibres: 7

partially of

coarse

aggregate concrete.

(iii) The fatigue life extension ratio (healing rate) of the fatigue damaged beams can be improved by induction heating, wherein the rate of healing is dependent on the higher level of microstrain developed.

(i) Steel wool fibers might negatively impact the abrasion loss performance of the asphalt concrete mixture when they are not homogeneously distributed, characterized by the appearance of fibre clusters.

(ii) The mechanical resistance of the test samples could be recovered up to $60 \%$ when the material was damaged. This happened at around $100^{\circ} \mathrm{C}$.

(i) The induction heating rate of the asphalt mixture can be increased with the suitable composition of steel fibres and steel slag. The order of heating rate for different asphalt mixtures is $\mathrm{SF}+\mathrm{SS}>\mathrm{SF}>\mathrm{SS}$. The selection of the right composition can facilitate homogenous heating and the efficiency of induction healing.

(ii) Incorporating steel slag or steel fibres may also improve the water stability, Marshall stability, and residual Marshall stability ratio. 
TABle 2: Continued.

\begin{tabular}{|c|c|c|c|c|c|c|c|}
\hline $\begin{array}{l}\text { Healing } \\
\text { Type }\end{array}$ & References & $\begin{array}{l}\text { Materials } \\
\text { Used }\end{array}$ & $\begin{array}{l}\text { Diameter } \\
\quad(\mu \mathrm{m})\end{array}$ & $\begin{array}{l}\text { Length } \\
(\mathrm{mm})\end{array}$ & $\begin{array}{l}\text { Temperature } \\
\text { Heating }\left({ }^{\circ} \mathrm{C}\right)\end{array}$ & $\begin{array}{l}\text { Duration of } \\
\text { Heating (s) }\end{array}$ & Relevant Conclusion \\
\hline
\end{tabular}

(i) Busy airports that face problems of runway closure can benefit from the microwave

Grade 3

$\begin{array}{ll}\text { Microwave } & \text { Tabaković } \\ \text { Heating } & \text { et al. [55] }\end{array}$
coarsegrained Trollull Steel Wool

IM8 Carbon fibres

5.2

6.35

Microwave Wang et al. Heating [56]

AS4 Carbon fibres

7.1

6.35

120 (at

$1100 \mathrm{~W}$ )

180 (at

$300 \mathrm{~W})$

healing process using steel fibres.

The addition of steel fibres with 3 min of microwave healing initiates a rapid healing process.

(ii) Optimum steel fibre content for the Porous Friction Course (PFC) mix is $5 \%$ with $300 \mathrm{~W}$ heating power.

(i) The electrical resistivity of the mastic can be decreased with an optimal addition of carbon fibres. It can even absorb more microwave energy for healing. Thus, less energy is required to heal cracks on using carbon fibres.

(ii) $3 \%$ of AS4 and $2 \%$ of IM8 carbon fibres by bitumen weight have the best healing performance.

(iii) The microwave energy was absorbed by the carbon fibre and heal the crack when the surface temperature went up to around $100^{\circ} \mathrm{C}$.

(i) Steel wool content of 3 and $5 \%$ by volume of bitumen have an excellent bonding between the fractured surfaces 24 hours after heating.

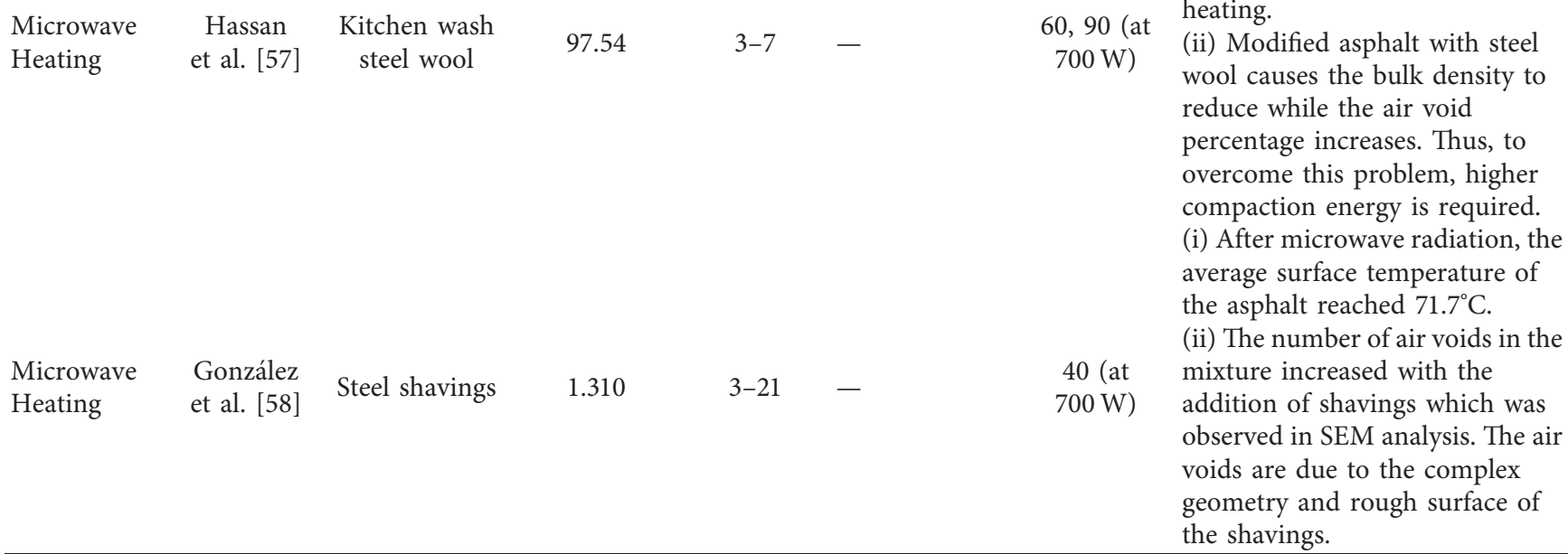

while the contact resistance depends on the resistance to current flow due to the surface conditions of both materials used. The heated binder usually exhibits Newtonian flow when its temperature reached $50^{\circ} \mathrm{C}$ depending on the source and composition of the asphalt binder as established by García [62], which helps fill the asphalt mixture cracks in a sort of capillary flow. The capillary pressure drives the binder to flow over crack space. However, such flow depends on the bituminous flow threshold as different types of bitumen exhibit different threshold temperatures for flow, depending on their rheological properties, usually ranging from $30^{\circ} \mathrm{C}$ to $70^{\circ} \mathrm{C}$. Menozzi et al. [63] claimed in their study that the flow behavior index, $n$ where it is near-Newtonian, occurs when the flow behavior index is within $0.9 \leq n<1$. It is the temperature where the Newtonian behavior occurs almost starting from $30^{\circ} \mathrm{C}$ and above. Hence, the microcracks heal and fill the binder while ensuring its bonding and adhesive strength have been restored [3]. Additionally, the flow 
TABLE 3: Comparison of recovery performance between the microwave and induction heating system.

\begin{tabular}{|c|c|c|c|c|c|c|}
\hline \multirow[t]{2}{*}{ Healing type } & \multirow[t]{2}{*}{ References } & \multirow[t]{2}{*}{$\begin{array}{c}\text { Optimum heating temperature or } \\
\text { duration of heating }\end{array}$} & \multicolumn{3}{|c|}{$\begin{array}{l}\text { Recovery performance of optimum steel } \\
\text { fibre content in term of strength at } \\
\text { optimum heating }\end{array}$} & \multirow[t]{2}{*}{ Healing index } \\
\hline & & & Initial & Pre-healing & Post-healing & \\
\hline $\begin{array}{l}\text { Induction } \\
\text { heating }\end{array}$ & Liu et al. [23] & 120 seconds & N/A & N/A & N/A & $\begin{array}{c}\text { Post-healing: } \\
100 \%\end{array}$ \\
\hline $\begin{array}{l}\text { Induction } \\
\text { heating }\end{array}$ & García et al. [24] & $100^{\circ} \mathrm{C}$ & N/A & $\mathrm{N} / \mathrm{A}$ & N/A & $\begin{array}{c}\text { Post-healing: } \\
60 \%\end{array}$ \\
\hline $\begin{array}{l}\text { Induction } \\
\text { heating }\end{array}$ & Liu et al. [52] & $85^{\circ} \mathrm{C}$ & $2.5 \mathrm{kN}$ & $\begin{array}{c}\text { Cycle 1: } 2.1 \mathrm{kN} \\
\text { Cycle 2: } 2 \mathrm{kN} \\
\text { Cycle 3: } 2 \mathrm{kN} \\
\text { Cycle } 4: 2 \mathrm{kN} \\
\text { Cycle } 1 .\end{array}$ & Cycle 5: $2 \mathrm{kN}$ & $\begin{array}{c}\text { Pre-healing: } \\
84 \% \\
\text { Post-healing: } \\
80 \%\end{array}$ \\
\hline $\begin{array}{l}\text { Induction } \\
\text { heating }\end{array}$ & Liu et al. [53] & $85^{\circ} \mathrm{C}$ & $2200 \mathrm{MPa}$ & $\begin{array}{l}2000 \mathrm{MPa} \\
\text { Cycle 2: } \\
2100 \mathrm{MPa} \\
\text { Cycle 3: } \\
1900 \mathrm{MPa}\end{array}$ & $\begin{array}{l}\text { Cycle } 4: \\
2000 \mathrm{MPa}\end{array}$ & $\begin{array}{l}\text { Pre-healing: } \\
\text { 86-95\% } \\
\text { Post-healing: } \\
\quad 91 \%\end{array}$ \\
\hline $\begin{array}{l}\text { Induction } \\
\text { heating }\end{array}$ & García et al. [54] & $100^{\circ} \mathrm{C}$ & N/A & N/A & N/A & $\begin{array}{c}\text { Post-healing: } \\
60 \%\end{array}$ \\
\hline $\begin{array}{l}\text { Induction } \\
\text { heating }\end{array}$ & Liu et al. [11] & $90^{\circ} \mathrm{C}$ & N/A & N/A & N/A & $\begin{array}{l}\text { Post-healing: } \\
52-70 \%\end{array}$ \\
\hline $\begin{array}{l}\text { Microwave } \\
\text { heating }\end{array}$ & $\begin{array}{l}\text { Tabaković et al. } \\
{[55]}\end{array}$ & 180 seconds (at $300 \mathrm{~W}$ ) & $2200 \mathrm{MPa}$ & $\begin{array}{l}\text { Cycle 1: } \\
1900 \mathrm{MPa}\end{array}$ & $\begin{array}{l}\text { Cycle 2: } \\
2000 \mathrm{MPa}\end{array}$ & $\begin{array}{l}\text { Pre-healing: } \\
86 \% \\
\text { Post-healing: } \\
91 \%\end{array}$ \\
\hline $\begin{array}{l}\text { Microwave } \\
\text { heating }\end{array}$ & Wang et al. [56] & 120 seconds (at $1100 \mathrm{~W}$ ) & $3.8 \mathrm{kN}$ & $\begin{array}{l}\text { Cycle 1: } 3.6 \mathrm{kN} \\
\text { Cycle 2: } 3.4 \mathrm{kN} \\
\text { Cycle 3: } 3.2 \mathrm{kN} \\
\text { Cycle 4: } 2.9 \mathrm{kN}\end{array}$ & Cycle 5: $2.9 \mathrm{kN}$ & $\begin{array}{l}\text { Pre-healing: } \\
\text { 76-94\% } \\
\text { Post-healing: } \\
76 \%\end{array}$ \\
\hline $\begin{array}{l}\text { Microwave } \\
\text { heating }\end{array}$ & $\begin{array}{c}\text { González et al. } \\
\text { [58] }\end{array}$ & 40 seconds (at $700 \mathrm{~W}$ ) & N/A & N/A & N/A & $\begin{array}{c}\text { Post-healing: } \\
50-60 \%\end{array}$ \\
\hline
\end{tabular}

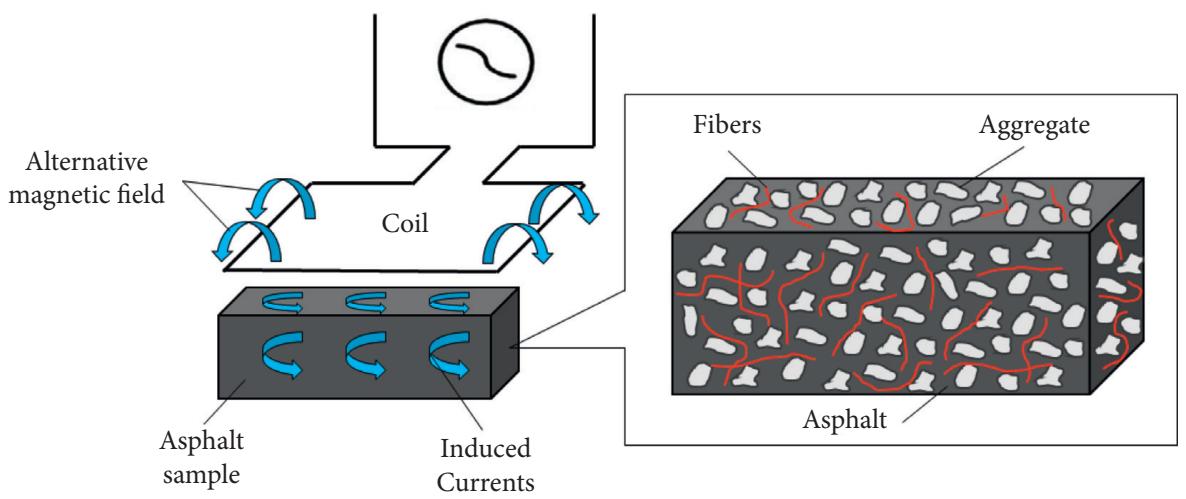

FIGURE 3: Schematic demonstration of induction healing mechanism for thermoplastic asphalt materials [3].

behavior index of the bitumen has also been found to be essential in characterizing the threshold for the initial selfhealing temperature of bitumen $[64,65]$. In the case of microcrack, molecular interdiffusion models can predict crack occurrences between binder and aggregate interfaces, while capillary flow healing models best describe the macrocracking self-healing phenomenon [66].

According to the simple model derived by García et al. [49] as in the following equation:

$$
\stackrel{q}{\text { in du ction }}^{\prime}=\frac{\pi r^{4} L_{e q}}{16 \rho} \mu_{m} B_{r} \omega^{2}
$$

where ${ }^{q}{ }_{\text {in }}^{\prime}$ du ction $=$ power dissipated by time unit, $r=$ radius of each individual fiber, $L_{\mathrm{eq}}=$ equivalent length or total length of fibers being heated, $\mu_{\mathrm{m}}=$ magnetic permeability of the mastic, $B_{\mathrm{r}}=$ resultant magnetic field, and $(\omega)=$ frequency of the alternating magnetic field. 
Based on the formula, the power dissipated per unit time is related to the total equivalent fibers length. The power exhibits a linearly increasing trend with an increase in the volume of fibers, wherein the relationship is valid until the percolation threshold is reached. Beyond that threshold point, the effective length will be the same for all sample widths wherein no more fibers can fit into the sample.

The process of induction heating, as mentioned earlier, is based on electromagnetic induction and Joule's heating, which can be expressed using electromagnetic induction Faraday's law. The electromotive force ( $\varepsilon$, in volts) and magnetic flux $\left(\phi_{-} B\right.$, in Webers) are related based on the following equation [2]:

$$
\varepsilon=-\frac{d \phi_{B}}{d t}
$$

Apart from that, Faraday's law emphasized that the strength of these currents and the magnetic field are linear to the magnitude of the current flowing through the coil. Electrically nonconductive bitumen requires particles that are conductive to be added to its mixture, such as steel fibers, to build closed loops of eddy currents and facilitate the transfer of electron energy between the bituminous and steel phases. Moreover, the induced electromotive force of steel fibers modified asphalt mixtures can be expressed as follows [2]:

$$
\varepsilon=\omega \cdot A \cdot B=2 \pi \cdot f \cdot A \cdot H \cdot \mu_{m},
$$

where $\omega$ is the frequency of the alternating magnetic field, $A$ is the enclosed loop area of the conductive fiber, $B$ is the magnetic flux, $f$ is the magnetic field frequency, $H$ is the magnetic field intensity, and $\mu_{m}$ is the magnetic permeability.

Based on Joule's effect, the eddy current heating the material is expressed as follows [2]:

$$
P=t \cdot I^{2} \cdot R \text {, }
$$

where $P$ is the heat generated per unit time, $t$ is the time of exposure to the magnetic field, $I$ is the constant current, and $R$ is the material resistance.

The following equation shows the relationship between the power generated and the source in the sample [2]:

$$
P=\frac{(2 \pi \cdot f \cdot A \cdot H \cdot \mu)^{2}}{R} .
$$

Equation (5) shows that the time required to heat a composite to a specific temperature decreases quadratically as the frequency increases. A phenomenon called the "skin effect" is observed during higher frequencies, wherein the penetration depth of the electromagnetic field might be limited, even though more power can be dissipated. Rudnev et al. [65] stated that the phenomenon depends on the occurrence of electromagnetic fields by induced currents, which have opposite field directions than the generating field (Figure 4). The penetration depth $d$ is expressed using Maxwell's formulations in the following equation [66]:

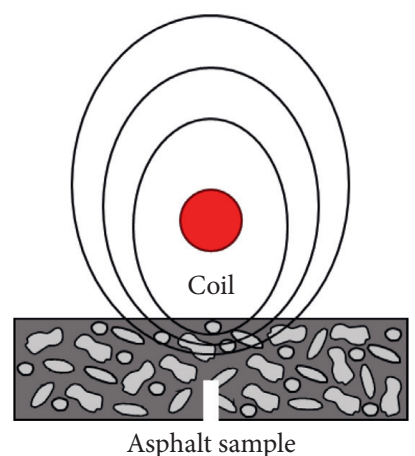

Figure 4: Schematic diagram of "skin effect" phenomenon [66].

$$
\delta=\sqrt{\frac{\rho}{\mu \cdot \pi \cdot f}}
$$

From equation (6), an inverse relationship between frequency and heating depth can be inferred, that is, higher frequency leads to a lower heating depth. Thus, it is essential to take into consideration the contributing factors in the selfhealing process, such as frequency and so on.

\section{Mechanism of Microwave Heating}

Another technology related to the self-healing of asphalt pavement is microwave radiation. Microwaves are electromagnetic (EM) waves is similar in nature to radar, ultraviolet (UV), and infrared (IR). Both the waves are differentiated from each other based on their wavelength (known as frequency). For example, ultraviolet has a wavelength between $4.3 \times 10^{-7} \mathrm{~m}$ and $3 \times 10^{-9} \mathrm{~m}$, while the wavelength of microwave ranges between $3 \mathrm{~mm}$ and $3 \mathrm{~m}$, corresponding to frequencies between $100 \mathrm{MHz}$ and $100 \mathrm{GHz}[42,67]$. A microwave oven typically functions at $2.45 \mathrm{GHz}$, which usually corresponds to an approximate wavelength of $120 \mathrm{~mm}[45,68,69]$.

Microwaves are nonionizing electromagnetic radiation that causes heating of the matter by oscillation, rotation, or vibrations of molecules [70]. Conventional processing methods involve heating the surface of materials while transferring the heat into the material via conduction, convection, and radiation modes. In contrast, in microwave heating, atomic level heating occurs, which gives rise to volumetric heating in the processed component [71]. The electromagnetic energy is converted into heat within the material during microwave heating. The heat generated in the core moves in the outward direction. The electromagnetic waves only increase the energy stored thermally by an object when they are absorbed. This phenomenon can be inferred that the more thermally stored energy within a material, the more the occurrence of vibration and oscillation of its molecules under electromagnetic radiation. Such an increase in vibration and oscillation of molecules in form of kinetic energy leads to the dissipation of heat energy within the material that can cause the increment of temperature [5]. However, the energy of electromagnetic radiation and its absorbance depends on the photon wavelength, that is, color that varies over a wide range. This 


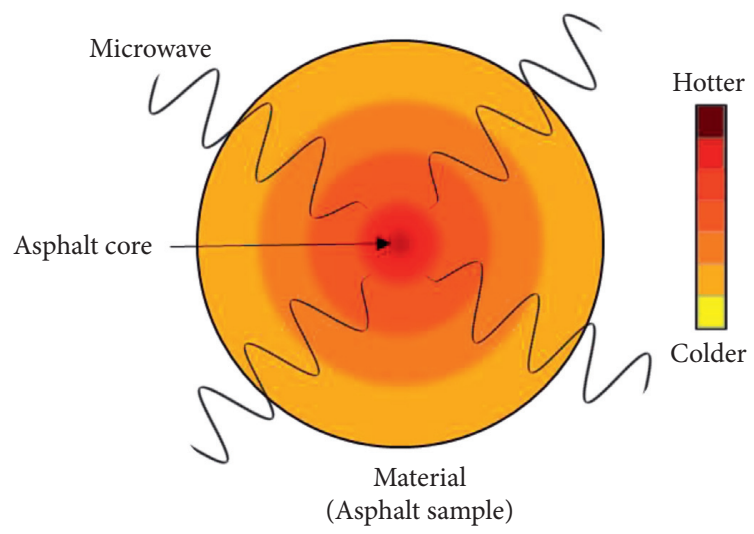

Figure 5: Phenomenon of heat generation in microwave heating [72].
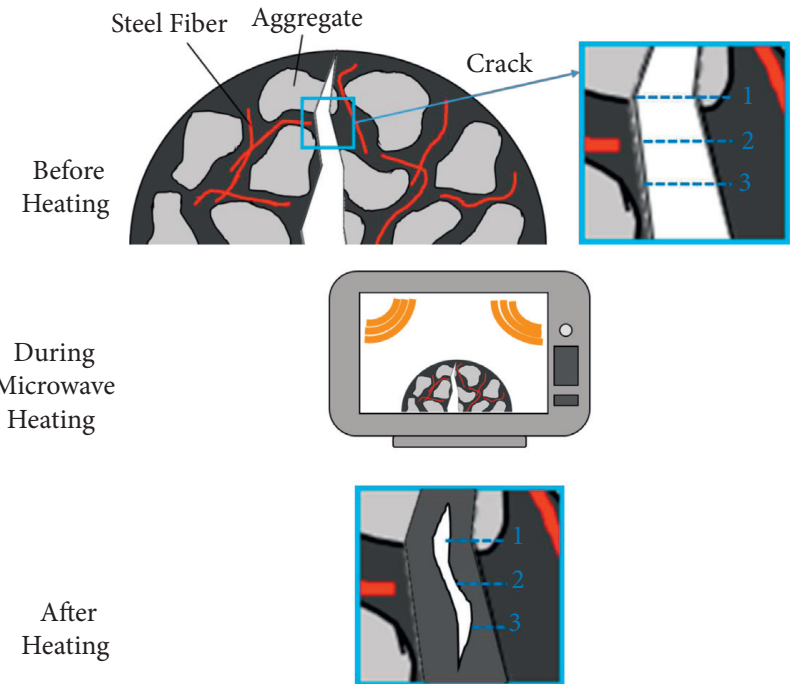

Figure 6: Schematic diagram of crack closure via microwave heating [38].

determines its rate of heat transfer, wherein, for instance, photon wavelengths of black surfaces have higher heat transfer rates than transparent surfaces, which makes the utilization of asphalt black surfaces incorporated with conductive materials very efficient in terms of heat transfer between the bitumen and conductor molecular interfaces. This phenomenon helps ensure uniform heat dissipation from the bituminous phase to the conductor phase, which leads to effective capillary flow in both phases. The heating mechanisms of asphalt in a microwave system are shown in Figure 5. An example of microwave heating towards the asphalt sample that can increase the temperature of the binder and close the crack is shown in Figure 6.

The EM waves can be absorbed by the steel fibers when they are placed in the microwave field. The steel fibers can absorb the microwaves and convert them to heat through a combination of different phenomena, such as double polarization, interface polarization, and electrical conduction dissipation [73]. The converted heat is passed on to the asphalt and aggregates. The effect of temperature on the asphalt at the time of microwave heating results in a
Newtonian flow of the asphalt, enabling it to fill the cracks in the mixture. On a microscale, the process of crack healing in a microscale can be considered to be characterized by a combination of capillary flow induced by the surface tension force, the gravity of liquid asphalt, and friction between aggregate particles and flowing asphalt. The recovery of adhesion strength occurs when the molecular diffusion and rebinding process occurs, while the binder flows into the microcrack space. The recovered strength was ascribed to two major aspects: the molecular diffusion in asphalt and the rebinding of asphalt and aggregates [54]. The healing mechanism of asphalt mixture via microwave heating is shown in Figure 7.

The efficiency materials in absorbing energy from microwave radiations, which ultimately induce increments in its temperature via the penetration of such wave into its molecular structure, can be expressed by its dielectric properties. Three related parameters in this field are as follows:

(1) The dielectric constant of the material $\left(\varepsilon^{\prime}\right)$ 


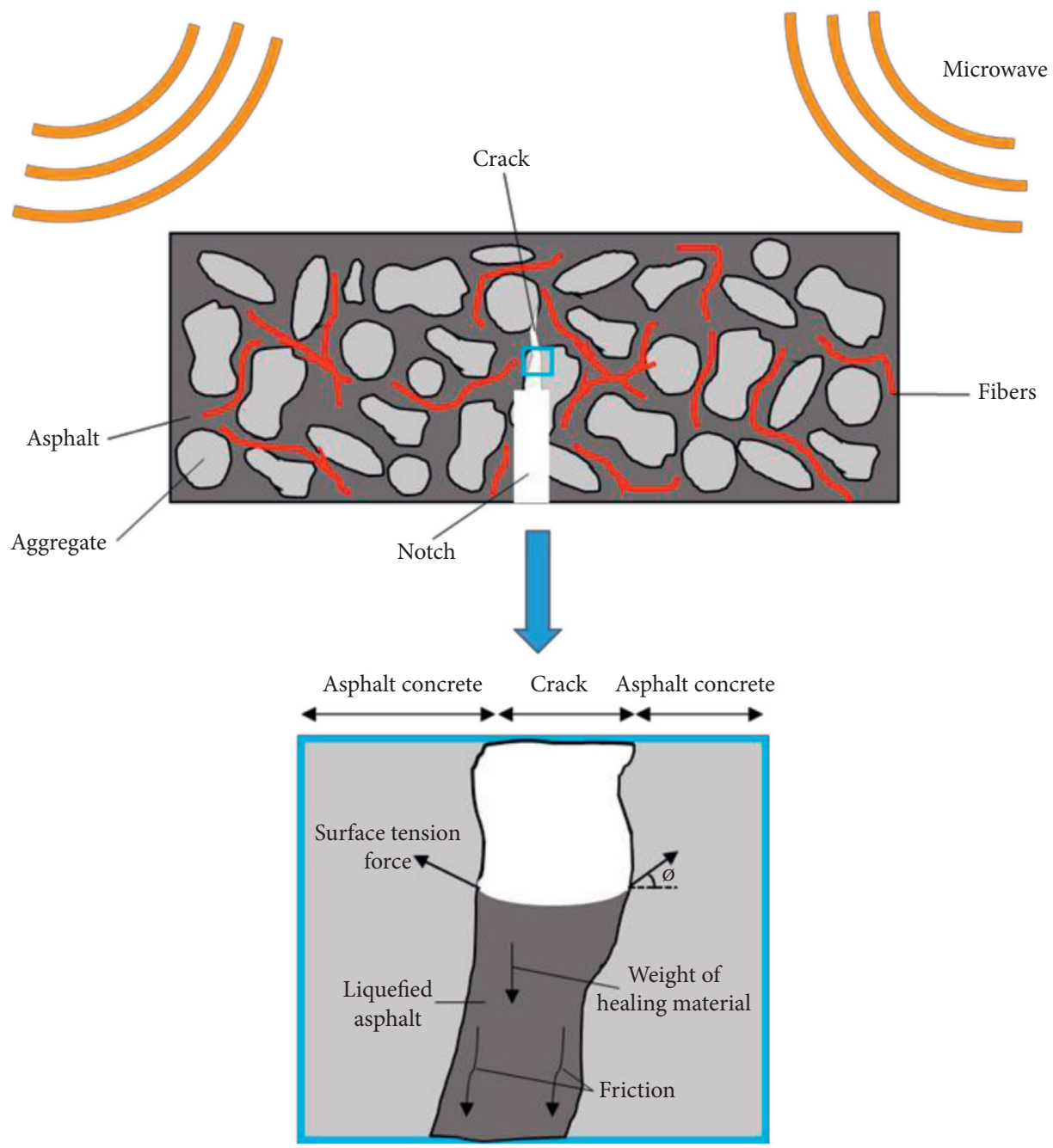

FIGURE 7: Schematic demonstration of microwave healing mechanism [54].

(2) The dielectric loss factor ( $\left.\varepsilon^{\prime \prime}\right)$

(3) The dissipation factor or loss tangent of the material $(\tan \delta)$

The dielectric constant $\left(\varepsilon^{\prime}\right)$ affect the electrical field energy that is stored within the material. The dielectric loss factor $\left(\varepsilon^{\prime \prime}\right)$ determines the value of that energy is dissipated in the form of heat, while the loss tangent, which equals $\varepsilon$ " $\varepsilon$, is the parameter that quantifies the inherent dissipation of electromagnetic energy [74]. By discovering these factors, several researchers such as Wan et al. [75] and Zhang et al. [76] are making an improvement to the ability of asphalt mixtures toward the microwave absorption via increment of the dielectric constant of asphalt mixtures.

\section{Conclusions and Way Forward}

An extensive review of the research works carried out on the advancement of self-healing has revealed that the method is a competent technology for road maintenance with a great potential to prolong the service life of asphalt pavements. The innovation of self-healing by using induction/microwave heating can help enhance the temperature absorption of the binder, which can help improve its fatigue resistance under repeated traffic loading. Such loads also inhibit the performance of pavements under various adverse weather and stress loading conditions. Asphalt self-healing processes mainly entail the wetting of nanocrack surfaces, diffusion of binder molecules between binder-aggregate interfaces, and the randomization of these diffused molecules, which help achieve the strength of cracked interfaces relatively similar to that of the original materials. Thus, self-healing is an effective method of enhancing the ability of asphalt pavement to heal, especially on microcracks healing.

Incorporating self-healing technologies into asphalt pavements leads to more durable roads and addresses environmental and economic challenges by lowering costs and emissions during maintenance and manufacturing processes. Such incorporation between sustainable materials can aid in developing asphalt pavements with self-healing technologies and construction of asphalt pavements as a whole. Moreover, these technologies can help reduce the consumption of natural resources, saving the cost of aggregates and bitumen that would otherwise be used in reconstruction or repair/maintenance actions of road networks while mitigating the effect of related costs and $\mathrm{CO}_{2}$ 
emissions, as well as minimizing the traffic disruptions during road construction cycles. Additionally, the utilization of renewable and sustainable materials on asphalt pavement construction has led to the quest for material efficiency, suitability, and productivity in both the fields of material and transportation engineering. Contrastingly, different materials may or may not be compatible with asphalt mixtures based on their nature and composition; materials such as steel and its by-product have been established to be suitable in improving asphalt mixture mechanical and healing strengths as a result of its efficient physical and conductive properties. Hence this review recommends further exploration concerning the effect of steel slags, wools, and fibers in terms of the impact of bituminous and steel free energy phases on healing while also taking into consideration the influence of chemical compositions on steel rusting and deterioration for a thorough understanding between steel and bitumen as a singular system.

\section{Data Availability}

The data used to support the findings of this study are included within the article.

\section{Conflicts of Interest}

The authors declare that they have no conflicts of interest.

\section{Acknowledgments}

The authors sincerely acknowledge the Ministry of Higher Education Malaysia for the Fundamental Research Grant Scheme with Project CODE: FRGS/1/2021/TK01/USM/02/1 that enabled us to conduct this research work. Support from Universiti Sains Malaysia via Research University Individual (RUI) Grant (1001.PAWAM.8014140) is also appreciated. Special thanks are due to all related staff for extending their support and continuous assistance.

\section{References}

[1] S. M. Abtahi, M. Sheikhzadeh, and S. M. Hejazi, "Fiberreinforced asphalt-concrete - a review," Construction and Building Materials, vol. 24, no. 6, pp. 871-877, 2010.

[2] D. Sun, G. Sun, X. Zhu et al., "A comprehensive review on self-healing of asphalt materials: mechanism, model, characterization and enhancement," Advances in Colloid and Interface Science, vol. 256, pp. 65-93, 2018.

[3] Q. Dai, Z. Wang, and M. R. Mohd Hasan, "Investigation of induction healing effects on electrically conductive asphalt mastic and asphalt concrete beams through fracture-healing tests," Construction and Building Materials, vol. 49, pp. 729$737,2013$.

[4] "Asia trade Hub," Available from: <https://malaysia. asiatradehub.com/Infrastructure/1476/Roads $>$. [10 May 2020]..

[5] B. Lou, A. Sha, D. M. Barbieri, Z. Liu, and F. Zhang, "Microwave heating properties of steel slag asphalt mixture using a coupled electromagnetic and heat transfer model," Construction and Building Materials, vol. 291, pp. 123248-123312, 2021.
[6] Y. Song, Z. Wang, Y. Zhou, and R. Hu, "Research on microwave heating performance of modified steel slag asphalt mixture," Advances in Mechanical Engineering, vol. 13, no. 4, pp. 168781402199047-7, 2021.

[7] R. Abejón, "Self-healing asphalt: a systematic b analysis for identification of hot research topics during the 2003-2018 period," Materials, vol. 14, no. 3, pp. 565-618, 2021.

[8] A. García, J. Norambuena-Contreras, and M. N. Partl, "Experimental evaluation of dense asphalt concrete properties for induction heating purposes," Construction and Building Materials, vol. 46, pp. 48-54, 2013.

[9] S. Xu, X. Liu, A. Tabaković, and E. Schlangen, "The prospect of microwave heating: towards a faster and deeper crack healing in asphalt pavement," Processes, vol. 9, no. 3, p. 507, $2021 \mathrm{~b}$.

[10] Ö. E. Yamaç, M. Yilmaz, E. Yalçın, B. V. Kök, J. NorambuenaContreras, and A. Garcia, "Self-healing of asphalt mastic using capsules containing waste oils," Construction and Building Materials, vol. 270, p. 121417, 2021.

[11] Q. Liu, B. Li, E. Schlangen, Y. Sun, and S. Wu, "Research on the mechanical, thermal, induction heating and healing properties of steel slag/steel fibers composite asphalt mixture," Applied Sciences, vol. 7, no. 10, p. 1088, 2017.

[12] N. Ruiz-riancho, T. Saadoon, A. Garcia, D. Grossegger, and R. Hudson-griffiths, "Optimisation of self-healing properties for asphalts containing encapsulated oil to mitigate reflective cracking and maximize skid and rutting resistance \% Passing Sieve Size (mm)," Construction and Building Materials, vol. 300, Article ID 123879, 2021.

[13] Q. Liu, E. Schlangen, M. van de Ven, and Á. García, "Healing of porous asphalt concrete via induction heating," Road Materials and Pavement Design, vol. 11, no. sup1, pp. 527$542,2010$.

[14] J. Qui, M. F. C. Van De Ven, S. Wu, J. Yu, and A. A. A. Molenaar, "Investigating the self healing capability of bituminous binders," Road Materials and Pavement Design, vol. 10, no. SI, pp. 81-94, 2009.

[15] H. Fischer, "Self-repairing material systems-a dream or a reality?” Natural Science, vol. 2, no. 8, pp. 873-901, 2010.

[16] G. van Bochove, "Self Healing Asphalt-extending the service life by induction heating of asphalt," in Proceedings of the 6th Eurasphalt \& Eurobitume Congress, June 2017.

[17] A. Tabaković and E. Schlangen, "Self-healing technology for asphalt pavements," Self-healing Materials, vol. 273, pp. 285-306, 2015.

[18] Y. Sun, S. Wu, Q. Liu, J. Hu, Y. Yuan, and Q. Ye, "Snow and ice melting properties of self-healing asphalt mixtures with induction heating and microwave heating," Applied Thermal Engineering, vol. 129, pp. 871-883, 2018.

[19] R. P. Wool and K. M. O'Connor, "A theory crack healing in polymers," Journal of Applied Physics, vol. 52, no. 10, pp. 5953-5963, 1981.

[20] B. Shu, M. Zhou, T. Yang et al., "The properties of different healing agents considering the micro-self-healing process of asphalt with encapsulations," Materials, vol. 14, no. 1, pp. 16-18, 2021.

[21] L. Minsk, "Electrically conductive asphaltic concrete," U.S. Patent, vol. 3, p. 573, 1969.

[22] Á. García, E. Schlangen, M. Van De Ven, and D. Van Vliet, "Induction heating of mastic containing conductive fibers and fillers," Materials and Structures, vol. 44, no. 2, pp. 499-508, 2011.

[23] A. García, M. Bueno, J. Norambuena-Contreras, and M. N. Partl, "Induction healing of dense asphalt concrete," Construction and Building Materials, vol. 49, pp. 1-7, 2013. 
[24] S. Xu, A. García, J. Su, Q. Liu, A. Tabaković, and E. Schlangen, "Self-healing asphalt review: from idea to practice," Advanced Materials Interfaces, vol. 5, no. 17, pp. 1800536-1800621, 2018.

[25] Á. García, E. Schlangen, M. van de Ven, and Q. Liu, "Electrical conductivity of asphalt mortar containing conductive fibers and fillers," Construction and Building Materials, vol. 23, no. 10, pp. 3175-3181, 2009.

[26] D. Sun, F. Yu, L. Li, T. Lin, and X. Y. Zhu, "Effect of chemical composition and structure of asphalt binders on self-healing," Construction and Building Materials, vol. 133, pp. 495-501, 2017.

[27] Y. Sun, S. Wu, Q. Liu et al., "Self-healing performance of asphalt mixtures through heating fibers or aggregate," Construction and Building Materials, vol. 150, pp. 673-680, 2017.

[28] J. Gao, H. Guo, X. Wang et al., "Microwave deicing for asphalt mixture containing steel wool fibers," Journal of Cleaner Production, vol. 206, pp. 1110-1122, 2019.

[29] J. Norambuena-Contreras, R. Serpell, G. Valdés Vidal, A. González, and E. Schlangen, "Effect of fibres addition on the physical and mechanical properties of asphalt mixtures with crack-healing purposes by microwave radiation," Construction and Building Materials, vol. 127, pp. 369-382, 2016.

[30] A. González, J. Valderrama, and J. Norambuena-Contreras, "Microwave crack healing on conventional and modified asphalt mixtures with different additives: an experimental approach," Road Materials and Pavement Design, vol. 20, no. sup1, pp. S149-S162, 2019.

[31] M. Ameri, S. Hesami, and H. Goli, "Laboratory evaluation of warm mix asphalt mixtures containing electric arc furnace (EAF) steel slag," Construction and Building Materials, vol. 49, pp. 611-617, 2013.

[32] Q. Liu, W. Yu, E. Schlangen, and G. Van Bochove, "Unravelling porous asphalt concrete with induction heating," Construction and Building Materials, vol. 71, pp. 152157, 2014.

[33] B. Lou, A. Sha, D. M. Barbieri, Z. Liu, F. Zhang, and W. Jiang, "Improved microwave heating uniformity and self-healing properties of steel slag asphalt containing ferrite filler," Materials and Structures, vol. 54, no. 1, pp. 1-14, 2021.

[34] B. Shu, L. Guo, B. Qiu et al., "Effect of encapsulation combined with microwave heating on self-healing performance of asphalt mixture," Journal of Renewable Materials, vol. 9, no. 10, pp. 1781-1794, 2021.

[35] J. Norambuena-Contreras and A. Garcia, "Self-healing of asphalt mixture by microwave and induction heating," $M a-$ terials \& Design, vol. 106, pp. 404-414, 2016.

[36] M. T. Bevacqua, T. Isernia, F. G. Praticò, and S. Zumbo, “A method for bottom-up cracks healing via selective and deep microwave heating," Automation in Construction, vol. 121, p. 103426, Article ID 103426, 2021.

[37] B. Liang, F. Lan, K. Shi, G. Qian, Z. Liu, and J. Zheng, "Review on the self-healing of asphalt materials: mechanism, affecting factors, assessments and improvements," Construction and Building Materials, vol. 266, p. 120453, Article ID 120453, 2021.

[38] J. Norambuena-Contreras and I. Gonzalez-Torre, "Influence of the microwave heating time on the self-healing properties of asphalt mixtures," Applied Sciences, vol. 7, no. 10, p. 1076, 2017.

[39] M. Atakan and K. Yildiz, "Farklı a metal ai?pabmiki?p," Journal of Polytechnic, vol. 1, no. 1, 2020.

[40] J. Liu, Z. Wang, H. Guo, and F. Yan, "Thermal transfer characteristics of asphalt mixtures containing hot poured steel slag through microwave heating," Journal of Cleaner Production, vol. 308, p. 127225, 2021.

[41] Y. Deng, J. Ma, T. Lu, and D. Sun, "Enhanced heating-healing performance of asphalt concrete modified with heterogenous microwave sensitive admixtures," Construction and Building Materials, vol. 299, p. 123949, 2021.

[42] A. Dulaimi, S. Al-busaltan, and M. Sadique, "The development of a novel, microwave assisted, half-warm mixed asphalt," Construction and Building Materials, vol. 301, p. 124043, Article ID 124043, 2021.

[43] F. Gulisano and J. Gallego, "Microwave heating of asphalt paving materials: principles, current status and next steps," Construction and Building Materials, vol. 278, p. 121993, Article ID 121993, 2021.

[44] Z. Wang, N. Dai, X. Wang, J. Zhang, and H. Guo, "Laboratory investigation on effects of microwave heating on early strength of cement bitumen emulsion mixture," Construction and Building Materials, vol. 236, p. 117439, 2020.

[45] J. Gallego, M. A. Del Val, V. Contreras, and A. Páez, "Heating asphalt mixtures with microwaves to promote self-healing," Construction and Building Materials, vol. 42, pp. 1-4, 2013.

[46] S. Xu, X. Liu, A. Tabaković, and E. Schlangen, "Experimental investigation of the performance of a hybrid self-healing system in porous asphalt under fatigue loadings," Materials, vol. 14 , no. 12 , p. 3415,2021 a.

[47] S. Fan, H. Zhu, H. Yuan, and C. Chen, "Fracture -healing properties of asphalt mixtures and microwave heating thermo-sensitivity analysis of their constituent materials," Journal of Cleaner Production, vol. 312, p. 127763, 2021.

[48] W. Zhang, D. Wang, and B. Han, "Self-healing concrete-based composites," Self-Healing Composite Materials, pp. 259-284, 2020.

[49] Á. García, E. Schlangen, M. Van De Ven, and Q. Liu, "A simple model to define induction heating in asphalt mastic," Construction and Building Materials, vol. 31, pp. 38-46, 2012.

[50] Q. Liu, E. Schlangen, and M. Van De Ven, "Induction healing of porous asphalt concrete beams on an elastic foundation," Journal of Materials in Civil Engineering, vol. 25, no. 7, pp. 880-885, 2013.

[51] Q. Liu, E. Schlangen, M. Van De Ven, G. Van Bochove, and J. Van Montfort, "Evaluation of the induction healing effect of porous asphalt concrete through four point bending fatigue test," Construction and Building Materials, vol. 29, pp. 403-409, 2012.

[52] A. García, J. Norambuena-Contreras, M. Bueno, and M. N. Partl, "Influence of steel wool fibers on the mechanical, termal, and healing properties of dense asphalt concrete," Journal of Testing and Evaluation, vol. 42, no. 5, p. 20130197, 2014.

[53] A. Tabaković, D. O’Prey, D. McKenna, and D. Woodward, "Microwave self-healing technology as airfield porous asphalt friction course repair and maintenance system," Case Studies in Construction Materials, vol. 10, p. e00233, 2019.

[54] Z. Wang, Q. Dai, D. Porter, and Z. You, "Investigation of microwave healing performance of electrically conductive carbon fiber modified asphalt mixture beams," Construction and Building Materials, vol. 126, pp. 1012-1019, 2016.

[55] S. Jendia, N. Hassan, K. Ramlawi, and H. Abu-aisha, "Study of the mechanical and physical properties of self-healing asphalt," Journal of Engineering Research and Technology, vol. 3, no. 4, p. 7, 2016.

[56] A. González, J. Norambuena-Contreras, L. Storey, and E. Schlangen, "Self-healing properties of recycled asphalt mixtures containing metal waste: an approach through 
microwave radiation heating," Journal of Environmental Management, vol. 214, pp. 242-251, 2018.

[57] M. Skaf, J. M. Manso, Á. Aragón, J. A. Fuente-Alonso, and V. Ortega-López, "EAF slag in asphalt mixes: a brief review of its possible re-use," Resources, Conservation and Recycling, vol. 120, pp. 176-185, 2017.

[58] S. Wu, L. Mo, Z. Shui, and Z. Chen, "Investigation of the conductivity of asphalt concrete containing conductive fillers," Carbon, vol. 43, no. 7, pp. 1358-1363, 2005.

[59] Á. García, E. Schlangen, M. v. d. Ven, and G. v. Bochove, "Optimization of composition and mixing process of a selfhealing porous asphalt," Construction and Building Materials, vol. 30, pp. 59-65, 2012.

[60] Á. García, "Self-healing of open cracks in asphalt mastic," Fuel, vol. 93, pp. 264-272, 2012.

[61] A. Menozzi, A. Garcia, M. N. Partl, G. Tebaldi, and P. Schuetz, "Induction healing of fatigue damage in asphalt test samples," Construction and Building Materials, vol. 74, pp. 162-168, 2015.

[62] Q. Liu, W. Yu, S. Wu, E. Schlangen, and P. Pan, "A comparative study of the induction healing behaviors of hot and warm mix asphalt," Construction and Building Materials, vol. 144, pp. 663-670, 2017.

[63] H. Xiang, Z. He, L. Chen, H. Zhu, and Z. Wang, "Key factors and optimal conditions for self-healing of bituminous binder," Journal of Materials in Civil Engineering, vol. 31, no. 9, Article ID 04019172, 2019.

[64] J. Gallego, F. Gulisano, V. Contreras, and A. Páez, “The crucial effect of re-compaction energy on the healing response of hot asphalt mortars heated by microwaves," Construction and Building Materials, vol. 285, p. 122861, 2021.

[65] V. Rudnev, D. Loveless, R. L. Cook, and M. Black, "Handbook of induction heating," Handbook of Induction Heating, vol. 2, Article ID 28904, 2002.

[66] T. Bayerl, M. Duhovic, P. Mitschang, and D. Bhattacharyya, "The heating of polymer composites by electromagnetic induction - a review," Composites Part A: Applied Science and Manufacturing, vol. 57, pp. 27-40, 2014.

[67] J. Tang, "Unlocking potentials of microwaves for food safety and quality," Journal of Food Science, vol. 80, no. 8, pp. E1776-E1793, 2015.

[68] C. Li, G. Zeng, M. Zhou et al., "Performance evolution of $\mathrm{Fe} 3 \mathrm{O} 4$ used in the production of sustainable self-healing asphalt materials," Journal of Cleaner Production, vol. 314, p. 127960, 2021.

[69] E. Yalcin, "Effects of microwave and induction heating on the mechanical and self-healing characteristics of the asphalt mixtures containing waste metal," Construction and Building Materials, vol. 286, p. 122965, 2021.

[70] L. Trigos, J. Gallego, and J. I. Escavy, "Heating potential of aggregates in asphalt mixtures exposed to microwaves radiation," Construction and Building Materials, vol. 230, p. $117035,2020$.

[71] S. Singh, D. Gupta, V. Jain, and A. K. Sharma, "Microwave processing of materials and applications in manufacturing industries: a Review," Materials and Manufacturing Processes, vol. 30, no. 1, pp. 1-29, 2015.

[72] P. R. Matli, R. A. Shakoor, and A. M. A. Mohamed, "Development of metal matrix composites using microwave sintering technique," Sintering of Functional Materials, 2018.

[73] N. Zhao, T. Zou, C. Shi, J. Li, and W. Guo, "Microwave absorbing properties of activated carbon-fiber felt screens (vertical-arranged carbon fibers)/epoxy resin composites,"
Materials Science and Engineering: B, vol. 127, no. 2-3, pp. 207-211, 2006.

[74] A. Benedetto and A. Calvi, "A pilot study on microwave heating for production and recycling of road pavement materials," Construction and Building Materials, vol. 44, pp. 351-359, 2013.

[75] P. Wan, Q. Liu, S. Wu et al., "A novel microwave induced oil release pattern of calcium alginate/nano- $\mathrm{Fe} 3 \mathrm{O} 4$ composite capsules for asphalt self-healing," Journal of Cleaner Production, vol. 297, p. 126721, 2021.

[76] Y. Zhang, L. Yang, J. Li, Q. Wang, and B. Guo, "Influence of the particle sizes and densities of RAP on microwave heating efficiency," Alexandria Engineering Journal, vol. 61, no. 1, pp. $65-71,2022$. 